\title{
Presynaptic Calcium Signals and Transmitter Release Are Modulated by Calcium-activated Potassium Channels
}

\author{
Richard Robitaille and Milton P. Charlton \\ Medical Research Council Group, Department of Physiology, University of Toronto, Toronto, Ontario, Canada M5S 1A8
}

The regulation of synaptic transmission by $\mathrm{Ca}^{2+}$-activated potassium (gKca) channels was investigated at the frog neuromuscular junction (nmj). Charybdotoxin (CTX), a blocker of certain types of gKca channels, induced a twofold increase of transmitter release. Similar results were obtained with purified natural toxin, synthetic toxin, and recombinant toxin. Apamin, a blocker of a different type of gKca channel, did not alter transmitter release. CTX was ineffective after intraterminal $\mathrm{Ca}^{2+}$ buffering was increased by application of the membrane-permeant $\mathrm{Ca}^{2+}$ buffer dimethyl-BAPTA-AM. $B y$ itself, the permeant buffer first caused a slight increase in transmitter release before release was eventually decreased. This increase of release did not occur when the buffer was applied in the presence of $\mathrm{CTX}$ or $\mathrm{Ba}^{2+}$, another gKca channel blocker. Stimulus-evoked entry of $\mathrm{Ca}^{2+}$ in nerve terminals, detected with the fluorescent $\mathrm{Ca}^{2+}$ indicator FLUO3, was increased after blockade of gKca channels by CTX. CTX had no effect on the amount or the time course of synaptic depression. The results are consistent with the hypothesis that CTX-sensitive gKca channels normally narrow the presynaptic action potential and thus, by indirectly regulating $\mathrm{Ca}^{2+}$ entry, can serve as powerful modulators of evoked transmitter release. In order to affect presynaptic action potentials, the gKca channels must be located close to $\mathrm{Ca}^{2+}$ channels.

The release of neurotransmitter is highly sensitive to $\mathrm{Ca}^{2+}$ entry into the presynaptic nerve terminal (Dodge and Rahamimoff, 1967; Katz and Miledi, 1968; Augustine et al., 1985, 1987; Augustine and Charlton, 1986). One mechanism by which $\mathrm{Ca}^{2+}$ entry can be regulated is by changing the amplitude or the duration of the action potential (AP) in the presynaptic terminal. If the presynaptic AP is prolonged by application of drugs that block voltage-gated $\mathrm{K}^{+}$channels, more $\mathrm{Ca}^{2+}$ channels are opened for a longer period. The resulting enhancement of $\mathrm{Ca}^{2+}$ entry increases transmitter release (Llinás et al., 1981, 1982; Augus-

\footnotetext{
Received June 5, 1991; revised Aug. 26, 1991; accepted Aug. 28, 1991.

We thank Drs. H. L. Atwood and P. S. Pennefather for critical reading of the manuscript and Dr. G. J. Augustine for reading of the manuscript and for helpful suggestions and discussions. We also thank Dr. G. J. Kaczorowski for supplying purified and synthetic charybdotoxin and Dr. H. Jackson for supplying the recombinant charybdotoxin. This work was supported by National Centers of Excellence and by a group grant ("Nerve Cells and Synapses") from the Medical Research Council of Canada to M.P.C. R.R. was supported by a Centennial Postdoctoral Fellowship from the Medical Research Council of Canada.

Correspondence should be addressed to Richard Robitaille, Department of Physiology, Medical Research Council Group and National Centers of Excellence, Medical Sciences Building, University of Toronto, Toronto, Ontario, Canada M5S $1 \wedge 8$.

Copyright (C) 1992 Society for Neuroscience $0270-6474 / 92 / 120297-09 \$ 05.00 / 0$
}

tine, 1990). In addition to voltage-gated $\mathrm{K}^{+}$channels, $\mathrm{Ca}^{2+}$ activated potassium (gKca) channels have also been detected in presynaptic terminals of several synapses (Augustine and Eckert, 1982; Bartschat and Blaustein, 1985; Mallart, 1985; A. J. Anderson et al., 1988; Lindgren and Moore, 1989; Morita and Barrett, 1990; Roberts et al., 1990; for general reviews of gKca, see Blatz and Magleby, 1987; Ewald and Levitan, 1987; Latorre et al., 1989; Marty, 1989). However, despite abundant evidence for their presence in nerve terminals, the role of gKca channels in the regulation of synaptic transmission remains unknown. The present work therefore secks to examine the rolc of these channels in synaptic transmission.

Because clustering of $\mathrm{Ca}^{2+}$ channels at release sites (Robitaille et al., 1990; Cohen et al., 1991) permits a large $\mathrm{Ca}^{2+}$ transient in the nerve terminal during synaptic transmission (Simon and Llinás, 1985; Augustine et al., 1987; Smith and Augustine, 1988; Roberts et al., 1990; Adler et al., 1991), it is possible that presynaptic gKca channels would be activated with consequent reduction of the duration and amplitude of the presynaptic AP (Lindgren and Moore, 1989; Morita and Barrett, 1990). This mechanism would provide a $\mathrm{Ca}^{2+}$-dependent constraint on the process of transmitter release by terminating the presynaptic AP and would provide an additional method by which transmitter release is controlled (Morita and Barrett, 1990). Moreover, gKca channels could also modulate use-dependent changes in synaptic efficacy such as synaptic depression (del Castillo and Katz, 1954; Betz, 1970; Kusano and Landau, 1975; Zucker, 1989) that may be associated with $\mathrm{Ca}^{2+}$ accumulation in the nerve terminal and consequent increase in activity of these channels.

\section{Materials and Methods}

Experiments were performed at $19 \pm 0.5^{\circ} \mathrm{C}$ on the cutaneous pectoris nerve-muscle preparation dissected from Rana pipiens frogs. The normal frog Ringer's solution contained (in mM) $120 \mathrm{NaCl}, 2 \mathrm{KCl}, 1$ $\mathrm{NaHCO}_{3}, 1.8 \mathrm{CaCl}_{2}$, and 5 HEPES. The low- $\mathrm{Ca}^{2+} / \mathrm{high}^{-\mathrm{Mg}^{2+}}$ physiological solution contained $0.5 \mathrm{mM} \mathrm{CaCl}_{2}$ and $3.6 \mathrm{mM} \mathrm{MgCl}_{2}$, with the remaining ions the same as in normal frog Ringer's. The $\mathrm{pH}$ of both solutions was adjusted to 7.2. Synaptic transmission was monitored by intracellular recordings in the muscle fiber using glass microelectrodes, and transmitter release was evoked by suprathreshold stimulation of the motor nerve at $0.2 \mathrm{~Hz}$. Responses were averaged in groups of 16 by a computer-based data acquisition system. Transmitter release was assayed by measuring nerve-evoked end-plate potentials (EPP), and spontaneous release, by measuring miniature end-plate potentials (MEPP). For the experiments performed in normal external $\mathrm{Ca}^{2+}$ concentration, muscle contractions were blocked by $\mu$-conotoxin GIIIA ( 25 $\mu \mathrm{M}$; BACHEM, Torrance, CA). This toxin, from the snail Conus geographus, blocks specifically the voltage-dependent sodium channels of the muscle fibers (Cruz et al., 1985; Gray and Olivera, 1988). Charybdotoxin (CTX; batch 1521, Alomone Labs, Jerusalem, Israel), a toxin from the venom of the scorpion Leirus quinquestriatus hebraeus, was used as a blocker of gKca channels with large and intermediate conductances 
A

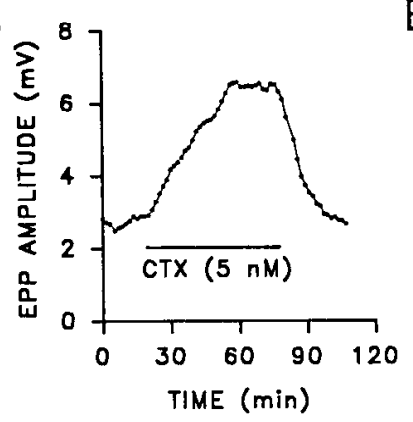

C

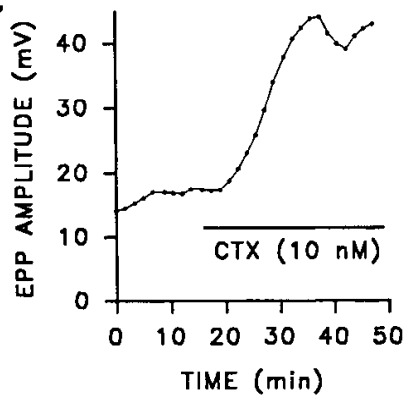

Figure 1. CTX increases transmitter release. $A$, EPP amplitude before, during, and after the application (bar) of CTX ( $5 \mathrm{nM}$ ) in low-Ca ${ }^{2+} /$ high$\mathrm{Mg}^{2+}$ physiological solution. Similar results were obtained in four other preparations. $B$, Superimposed EPPs recorded during control period and at the maximum effect of CTX ( $5 \mathrm{nM}$ ) (from the same nmj as $A$ ). $C$, EPP amplitude before and after the application (bar) of CTX (10 nM) in normal physiological solution containing $1.8 \mathrm{mM} \mathrm{Ca}^{2+}$ and 25 $\mu \mathrm{M} \mu$-conotoxin GIIIA. Similar results were obtained in seven preparations. $D$, Superimposed EPPs recorded during the control period and at the maximum effect of CTX (10 nM) (from the same nmj as $C ; C$ and $D$ are from a different experiment than $A$ and $B$ ). Each point in $A$ and $C$ represents the average of 16 EPPs obtained with stimulation at $0.2 \mathrm{~Hz}$. Calibration: $B, 1.0 \mathrm{mV}, 2 \mathrm{msec} ; D, 10 \mathrm{mV}, 2 \mathrm{msec}$.

(Castle et al., 1989). HPLC performed by the supplier indicated that the toxin was pure at $98 \%$, and only one fraction was present. The toxin we used was shown by the supplier to block outward currents at frog neuromuscular junctions (nmjs) using the perineural sheath recording technique of A. J. Anderson et al. (1988). We also used purified natural and synthetic (Sugg et al., 1990) CTX from the laboratory of G. J. Kaczorowski (Merck, Sharp and Dohme Research Laboratories, Rahway, NJ) and recombinant CTX from Natural Products Inc. (Salt Lake City, UT). Apamin (Research Biochemicals Inc., Natick, MA), a toxin from the honey bee (Apis mellifera), was used as a blocker of the smallconductance gKca channels (Castle et al., 1989). The purity of the toxin was also confirmed by the supplier to be more than $98.5 \%$ pure, and an HPLC analysis revealed the presence of only one fraction. Stock solution of 3,4-diaminopyridine $(3,4 \mathrm{D} \Lambda \mathrm{P})$ (Sigma) was prepared in distilled water and used at a concentration of $1 \mu \mathrm{M}$ in physiological saline.

Stock solution (5 mM) of the $\mathrm{Ca}^{2+}$ chelator 5,5'-dimethyl-1,2-bis(2aminophenoxy)ethane- $N, N, N^{\prime}, N^{\prime}$-tetraacetic acid acetoxymethyl ester (DMBAPTA-AM; Molecular Probes, Eugene, OR) was prepared in dimethyl sulfoxide (DMSO) and was used in saline at concentrations of 10 or $25 \mu \mathrm{M}$. Four ester groups attached to the $\mathrm{Ca}^{2+}$ binding site of DMBAPTA confer membrane permeability to DMBAPTA-AM. Once inside the cell, the esters are removed by esterases, and the active form of DMBAPTA (tetra-anionic form) is then trapped inside the cell and acts as an intracellular $\mathrm{Ca}^{2+}$ buffer. DMBAPTA-AM by itself does not bind $\mathrm{Ca}^{2+}$ and therefore does not alter extracellular $\mathrm{Ca}^{2+}$ (Tsien, 1981) Stock solution ( $5 \mathrm{~mm}$ ) of the membrane-permeant form of the $\mathrm{pH}$ indicator 2',7'-bis-(2-carboxyethyl)-5(and-6)-carboxyfluorescein (BCECFAM) was prepared in DMSO and was used in salinc at a concentration of $25 \mu \mathrm{M}$. Both control and experimental solutions used for the $\mathrm{Ca}^{2+}$ buffer and BCECF-AM experiments contained 1\% v/v DMSO.

Synaptic depression was studied in normal extracellular $\mathrm{Ca}^{2+}$ concentration after muscle contraction was blocked with $\mu$-conotoxin GIIIA
$(25 \mu \mathrm{M})$, and depression was induced by a train of stimuli at $40 \mathrm{~Hz}$ for $20 \mathrm{sec}$ or at $100 \mathrm{~Hz}$ for $10 \mathrm{sec}$.

In the intracellular electrophysiological experiments reported here, transmitter release was continuously monitored by recording EPPs in the same muscle fiber before and during the application of the $\mathrm{Ca}^{2+}$ buffer, toxins, $\mathrm{Ba}^{2+}$, or high-frequency stimulation. Most of the experiments were performed with flowing saline $(2 \mathrm{ml} / \mathrm{min})$, and a few were performed in a static bath.

For imaging $\mathrm{Ca}^{2+}$ entry in the nerve terminals, frog nmjs were loaded with the membrane-permeant form of the fluorescent $\mathrm{Ca}^{2+}$ indicator FLUO-3 (Molecular Probes; Tsien, 1989), which increases fluorescence with $\mathrm{Ca}^{2+}$. Solutions of FLUO-3-AM $(10 \mu \mathrm{M})$ were prepared in normal frog Ringer's solution containing a final concentration of $1 \% \mathrm{v} / \mathrm{v}$ of DMSO and $0.02 \%$ pluronic acid (Molecular Probes), a detergent that facilitates the indicator loading. Muscles were incubated for $60-75 \mathrm{~min}$ at room temperature $\left(18-20^{\circ} \mathrm{C}\right)$. Heavy metals were partially chelated with tetrakis (2-pyridylmethyl)ethylenediamine (TPEN; $20 \mu \mathrm{M}$; Molecular Probes; Arslan et al., 1985) added to the saline. Changes of fluorescence intensity were observed with a BioRad 600 confocal microscope (Shotton, 1989) using a $40 \times(0.55 \mathrm{NA})$ Nikon or a $50 \times(1.0 \mathrm{NA})$ Leitz water-immersion objective. The $488 \mathrm{~nm}$ excitation line of the laser was attenuated to $1 \%$ of the maximum power, and emission was detected through a low-pass emission filter with cutoff at $515 \mathrm{~nm}$. The experiments were performed in normal extracellular $\mathrm{Ca}^{2+}$ concentration, and muscle contractions were prevented by blocking the cholinergic receptors with $\alpha$-bungarotoxin (10 $\mu \mathrm{g} / \mathrm{ml}$; Molecular Probes). An image (average of four consecutive images) was taken before and $1 \mathrm{sec}$ after the beginning of the stimulation $(200 \mathrm{~Hz})$. The fluorescence intensity $(F)$ was averaged over the area of several branches of each nerve terminal, and the fluorescence change induced by the stimulation was expressed as

$$
\Delta F / F=\left(F_{\text {stimulation }}-F_{\text {resst }}\right) / F_{\text {ress }} .
$$

Under some conditions, perisynaptic Schwann cells at the nmj (see Fig. $4 E$ ) can accumulate FLUO-3, but this was not observed in the experiments reported here.

All values are expressed as mean \pm standard error of the mean, and $n$ represents the number of experiments performed.

\section{Results}

We investigated the role of gKca channels at frog nmjs, where synaptic transmission is well studied and where the presence of gKca channels has bcen established (David and Yaari, 1986; A. J. Anderson et al., 1988). Our strategy was to employ pharmacological blockers of gKca channels and additionally to prevent the activation of gKca channels by increasing intracellular $\mathrm{Ca}^{2+}$ buffering. We assayed the effects of these treatments on transmitter release by measuring nerve-evoked EPPs and spontaneous MEPPs.

\section{CTX increases transmitter release}

If the nerve terminal does have gKca currents that limit the duration of the AP, then a blocker of these channels should cause transmitter release to increase due to broadening of the AP. CTX was used as a specific blocker of gKca channels with large and intermediate conductances (Castle and Strong, 1986; Smith et al., 1986; C. S. Anderson et al., 1988; Gimenez-Gallego et al., 1988; MacKinnon and Miller, 1988; Castle et al., 1989; Massefski ct al., 1990). CTX has been shown to induce AP broadening in mammalian hippocampal cells (Lancaster and Nicoll, 1987; Storm, 1987a), in bullfrog ganglion neurons (Goh and Pennefather, 1987), and in lizard motor nerve terminals (Morita and Barrett, 1990). CTX induced a significant increase of transmitter release (Student's $t$ test, $p<0.05$ ) in every experiment, and Figure 1 illustrates a typical experiment. We found that the application of 2-10 $\mathrm{nm}$ CTX on the frog $\mathrm{nmj}$ induced an average increase of transmitter release of $163.6 \pm 58.7 \%$ (mean $\pm \mathrm{SE} ; n=5$ ) when measured in low-Ca ${ }^{2+} / \mathrm{high}-\mathrm{Mg}^{2+}$ physiological solution (Fig. $1 A, B$ ). The increase was persistent 
in the presence of CTX but reversed completely within 10-15 min when the toxin was removed (Fig. $1 A$ ). Similar effects on transmitter release were obtained with synthetic or recombinant CTX.

In order to assess the relevance of these results to transmitter release under normal physiological conditions, we next asked whether CTX would increase transmitter release in normal $\mathrm{Ca}^{2+}$ saline. In normal saline, EPPs are large enough to trigger a muscle AP and consequent contractions. To prevent muscle contractions, we applied $\mu$-conotoxin GIIIA $(25 \mu \mathrm{M})$, which blocks muscle but not nerve $\mathrm{Na}^{+}$channels (Cruz et al., 1985; Gray and Olivera, 1988). Similar results were obtained with 2 or $10 \mathrm{nM}$ CTX, so the results of these experiments were pooled. Under these conditions, large EPPs (17.22 $\pm 3.04 \mathrm{mV} ; n=7)$ could be recorded that were increased $113.48 \pm 25 \%(n=7$; Student's $t$ test, $p<0.05$ ) by the application of CTX ( 2 or 10 $\mathrm{nM})$. This indicates that $\mathrm{gKca}$ channels modulate synaptic transmission in the normal ionic environment (Fig. $1 C, D$ ).

If CTX had caused a tonic depolarization of the presynaptic terminal, the frequency of MEPPs would have increased due to opening of voltage-gated $\mathrm{Ca}^{2+}$ channels. In addition, if CTX had affected postsynaptic mechanisms, MEPP amplitude would have changed. In four of the experiments in normal $\mathrm{Ca}^{2+}$, all of which showed increased EPP amplitude with CTX, the average MEPP frequency was $1.34 \pm 0.25 \mathrm{~Hz}$ before CTX and $1.23 \pm 0.24 \mathrm{~Hz}$ after CTX (10 nM). In the same four experiments, MEPP amplitude was, on average, $690 \pm 60 \mu \mathrm{V}$ before and $760 \pm 63 \mu \mathrm{V}$ after CTX. We did not measure MEPPs in the remaining experiments. In no single experiment was there a significant difference in MEPP amplitude or frequency between control and CTX saline (Student's $t$ test, $p>0.05$ ). Thus, we conclude that the main effect of CTX is on presynaptic mechanisms that govern evoked release of transmitter.

\section{Apamin does not affect transmitter release}

To determine whether other types of gKca channels could also regulate transmitter release, we applied the toxin apamin, which is a specific blocker of the small-conductance gKca channels (Castle et al., 1989). In low-Ca ${ }^{2+} /$ high- $\mathrm{Mg}^{2+}$ saline, apamin (50 nM; $n=4)$ did not affect transmitter release, MEPP frequency, or MEPP amplitude (data not shown), although this concentration is known to block the small-conductance gKca channels (Castle et al., 1989).

\section{Intracellular $\mathrm{Ca}^{2+}$ buffers block the effect of CTX}

If CTX acts specifically on gKca channels, its effects on transmitter release should be reduced if the presynaptic $\mathrm{Ca}^{2+}$ transient is attenuated by an intracellular $\mathrm{Ca}^{2+}$ buffer because less $\mathrm{Ca}^{2+}$ would be available to activate the channels. We tested this hypothesis by applying CTX after a $\mathrm{Ca}^{2+}$ buffer had been loaded into the nmjs.

Transmitter release was recorded in low $-\mathrm{Ca}^{2+} / \mathrm{high}-\mathrm{Mg}^{2+}$ physiological solution, and frog nmjs were loaded with a membrane-permeant $\mathrm{Ca}^{2+}$ buffer (DMBAPTA-AM) that does not alter extracellular $\mathrm{Ca}^{2+}$ (see Materials and Methods; Tsien, 1981). In each of 15 experiments, DMBAPTA-AM (10-25 $\mu \mathrm{M})$ caused a significant reduction in transmitter release $(44.2 \pm 3.1 \%$; Student's $t$ test, $p<0.05$; Fig. 2). This is consistent with the known effects of $\mathrm{Ca}^{2+}$ buffers on transmitter release (Adler et al., 1991). Cleavage of the AM group from the $\mathrm{Ca}^{2+}$ chelator may induce changes in intracellular $\mathrm{pH}$ and produce formaldehyde residues (Tsien, 1981; Garciá-Sancho, 1985; Rhoda et al., 1985). If the reduction of transmitter release is secondary to the cleavage of the ester groups, the same effect on release should be obtained using a molecule that does not bind $\mathrm{Ca}^{2+}$. We tested this possibility by loading the frog nmjs with the membranc-permeant form of the $\mathrm{pH}$ indicator BCECF-AM, which has no affinity for $\mathrm{Ca}^{2+}$ (Rink et al., 1982). In four experiments performed in low$\mathrm{Ca}^{2+} /$ high- $\mathrm{Mg}^{2+}$ saline, BCECF-AM $(25 \mu \mathrm{M})$ did not affect the amount of evoked transmitter release or the size or frequency of MEPPs (data not shown). The reduction of release by the $\mathrm{Ca}^{2+}$ buffer is therefore caused by its $\mathrm{Ca}^{2+}$-binding activity.

In five experiments performed in low- $\mathrm{Ca}^{2+} /$ high- $\mathrm{Mg}^{2+}$ saline, CTX (2-10 nM) did not induce any increase in transmitter release when applied after the $\mathrm{Ca}^{2+}$ chelator had its maximal effects on release (Fig. $2 A, B$ ). In separate experiments, we found that the ability of CTX to increase release was not diminished by the presence of the $1 \%$ DMSO used in the buffer experiments. The failure of CTX to increase release in the presence of intracellular $\mathrm{Ca}^{2+}$ buffer indicates that the CIX effects are due solely to its interactions with channels activated by $\mathrm{Ca}^{2+}$. If the main effect of CTX is to block voltage-gated $\mathrm{K}^{+}$channcls (Schweitz et al., 1989), it should still have induced spike broadening and increased transmitter release in the presence of an intracellular $\mathrm{Ca}^{2+}$ buffer because the activation of these channels is not $\mathrm{Ca}^{2+}$ dependent. To determine if any $\mathrm{K}^{+}$channel blocker could work in the presence of the $\mathrm{Ca}^{2+}$ buffer, we applied 3,4DAP, a type of drug that blocks voltage-gated $\mathrm{K}^{+}$channels (Kirsch and Narahashi, 1978) and that causes presynaptic AP broadening in the squid giant synapse (Augustine, 1990). Indeed, a small concentration $(1 \mu \mathrm{M})$ of 3,4DAP induced a twofold increase of transmitter release when applied either before or after loading with the $\mathrm{Ca}^{2+}$ buffer (Fig. $2 C ; n=3$ ). Thus, as in the squid giant synapse (Adler et al., 1991), the presence of the $\mathrm{Ca}^{2+}$ buffer does not prevent blockade of voltage-gated $\mathrm{K}^{+}$channels, and any effect of CTX on these channels should still have been evident in the presence of the buffer. We therefore conclude that the main effect of CTX is not on voltage-gatcd $\mathrm{K}^{+}$channels.

\section{Intracellular $\mathrm{Ca}^{2+}$ buffers temporarily increase transmitter release}

While application of intracellular $\mathrm{Ca}^{2+}$ buffer eventually reduced transmitter release, the first noticeable effect was, paradoxically, a transient increase of release by $26.8 \pm 6.3 \%(n=15)$ that always occurred within 5-10 min (asterisks, Figs. $2 A, B ; 3 A$ ). We wondered whether the early increase in neurotransmitter release caused by the buffer was another indication that the buffer prevented the activation of gKca channels by attenuating the $\mathrm{Ca}^{2+}$ transient. This reduction in gKca channel opening would result in broadening of the presynaptic AP, which in turn would cause a larger entry of $\mathrm{Ca}^{2+}$ in the synapse. In this scenario, the increase of transmitter release would only be temporary because the concentration of $\mathrm{Ca}^{2+}$ chelator inside the nerve terminal would continuc to increase and eventually would compete for $\mathrm{Ca}^{2+}$, with the $\mathrm{Ca}^{2+}$ binding sites responsible for transmitter release.

If this hypothesis is correct, the buffer-induced increase in transmitter release should not occur if the buffer were applied after blockade of gKca channels. The results of two experiments designed to test this possibility are illustrated in Figure $3, B$ and $C$. We found, as predicted, that DMBAPTA-AM ( $25 \mu \mathrm{M})$ applied after 2 nM CTX did not induce the early increase of transmitter release $\left(n=5\right.$; Fig. $3 B$ ). The $\mathrm{Ca}^{2+}$ buffer induced a significant decrease of release ( $46.0 \pm 2.6 \%$; Student's $t$ test, $p<0.05$ ), 

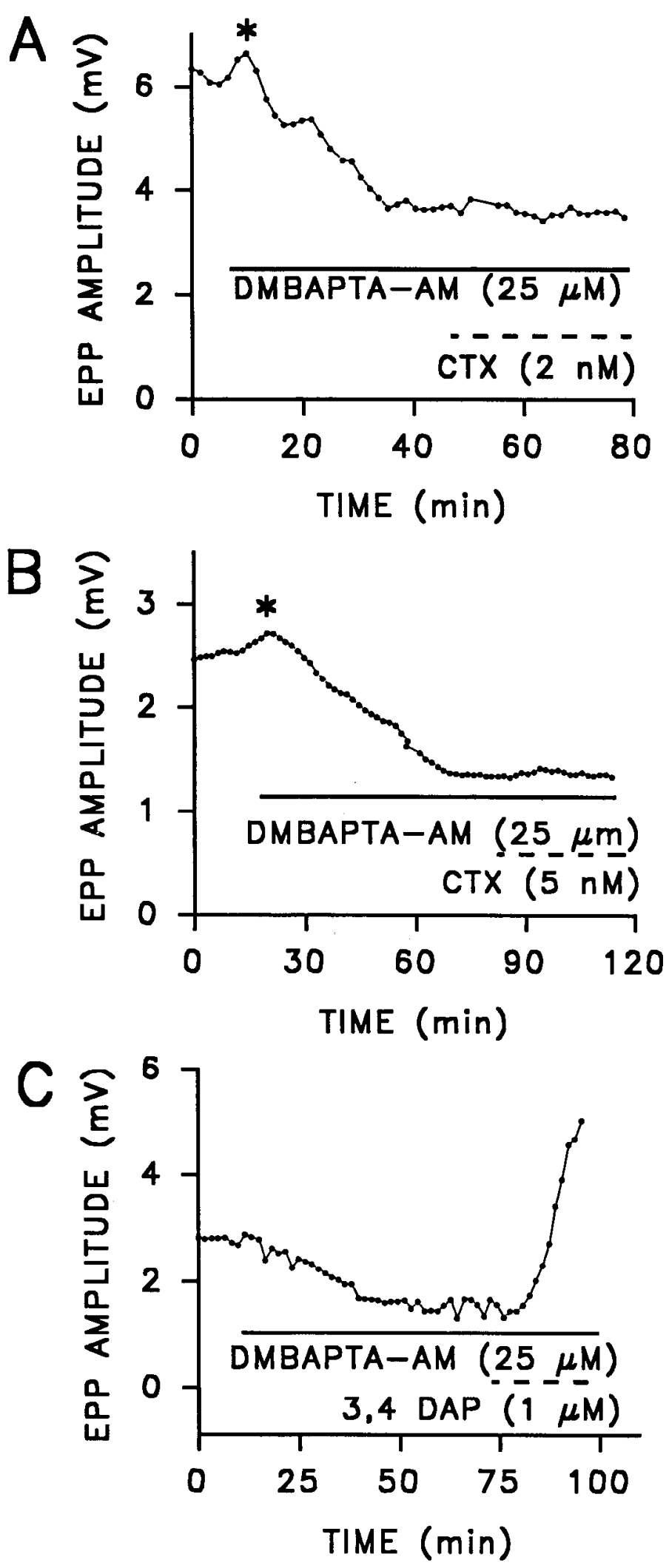

Figure 2. CTX does not increase transmitter release when intracellular $\mathrm{Ca}^{2+}$ buffering is elevated. $A$ and $B$, Application of membrane-permeant $\mathrm{Ca}^{2+}$ buffer (DMBAPTA-AM, $25 \mu \mathrm{M}$ ) (solid bar) onto two different preparations induced a transient increase in transmitter release (asterisks) followed by a reduction in release. CTX ( 2 or $5 \mathrm{nM}$ ) was then applied (broken bar), and no increase in transmitter release could be detected. Similar results were obtained in five preparations. $C$, A blocker of voltage-gated $\mathrm{K}^{+}$channels, 3,4DAP, increases transmitter release similar to that found in the absence of gKca channel blockade. The early increase was also blocked when the frog nmjs were loaded with DMBAPTA-AM $(25 \mu \mathrm{M})$ in the presence of $2 \mathrm{mM}$ $\mathrm{Ba}^{2+}$, a gKca channel blocker that can permeate $\mathrm{Ca}^{2+}$ channels (Mallart, 1985; Castle et al., 1989; Latorre et al., 1989). The decrease of release induced by the buffer still occurred in these conditions ( $n=4$; Fig. $3 C$ ). The blockade of the buffer-induced increase in transmitter release by CTX and $\mathrm{Ba}^{2+}$ therefore indicates that the increase is due to prevention, by the buffer, of gKca channel activation. Concentrations of $\mathrm{Ba}^{2+}$ lower than 2 $\mathrm{mM}(0.2-1.5 \mathrm{~mm})$ were inefficient in blocking the early increase but still increased MEPP frequency and quantal content and caused depolarization of the muscle fibers (Silinsky, 1978).

\section{$C T X$ increases $\mathrm{Ca}^{2+}$ entry during nerve stimulation}

The increase in transmitter release after blockade of gKca may be caused by increased entry of $\mathrm{Ca}^{2+}$ induced by broadening of the presynaptic AP. We tested this hypothesis by imaging $\mathrm{Ca}^{2+}$ entry in the nerve terminal using the fluorescent, membranepermeant $\mathrm{Ca}^{2+}$ indicator FLUO-3-AM (Tsien, 1989). The fluorescence was monitored using a BioRad 600 confocal microscope, and data are presented as false color images. A typical frog $\mathrm{nmj}$ with branching threadlike structure several hundred microns long is shown in Figure 4. Pixel intensities are coded so that the higher fluorescence intensities and hence higher $\mathrm{Ca}^{2+}$ activities are red and the lower ones are blue. Figure $4 A$ illustrates the resting level of fluorescence before nerve stimulation (resting level of $\mathrm{Ca}^{2+}$ ), and Figure $4 B$ illustrates the response of the same nerve terminal when stimulated at $200 \mathrm{~Hz}$ for $1 \mathrm{sec}$. In the absence of CTX, the typical increase in fluorescence intensity $(\Delta F / F)$ during nerve stimulation was $123 \pm 30 \%(n=$ 3 ). These stimulus-dependent fluorescence increases ceased when $\mathrm{Ca}^{2+}$ was removed from the saline or when the $\mathrm{Ca}^{2+}$ channel blockers $\mathrm{Cd}^{2+}(10 \mu \mathrm{M})$ or $\omega$-conotoxin GVIA $(1 \mu \mathrm{M}$; Kerr and Yoshikami, 1984) were applied. This indicates that the fluorescence signals are due to stimulus-dependent influx of $\mathrm{Ca}^{2+}$ into the presynaptic terminal. Figure $4, C$ and $D$, shows that, after application of CTX (10 nM), stimulus-dependent $\mathrm{Ca}^{2+}$ entry was increased. In three experiments, we did not detect any changes in the resting level of fluorescence after CTX (compare Fig. $4 A, C$ ), but the average $\mathrm{Ca}^{2+}$ signal following nerve stimulation was increased by $44 \pm 6 \%(\Delta F / F=178 \pm 33 \%$; Student's $t$ test, $p<0.05$ ). Because FLUO-3 must also act as a $\mathrm{Ca}^{2+}$ buffer, the effectiveness of CTX in the presence of this indicator may appear to contradict our earlier observation (Fig. 2) that CTX is ineffective in the presence of DMBAPTA. However, it must be remembered that the FLUO-3 experiments were performed in normal $\mathrm{Ca}^{2+}$ saline, where $\mathrm{Ca}^{2+}$ buffers have little effect ( $\mathrm{R}$. Robitaille and M. P. Charlton, unpublished observations) and that the affinity of FLUO-3 for $\mathrm{Ca}^{2+}$ is about $1 / 10$ that of DMBAPTA. Thus, under normal $\mathrm{Ca}^{2+}$ conditions, FLUO-3 may not have been able to prevent activation of gKca. To test this hypothesis, we applied FLUO-3-AM $(10 \mu \mathrm{M})$ in the presence of $\mu$-conotoxin GIIIA in normal $\mathrm{Ca}^{2+}$ saline and measured transmitter release with extracellular multiunit recordings (Mallart

even when intracellular $\mathrm{Ca}^{2+}$ buffering is elevated. 3,4DAP $(1 \mu \mathrm{M})$ was applied after the full effect of DMBAPTA-AM $(25 \mu \mathrm{M})$ on release was obtained. Each point in $A-C$ represents the average of 16 EPPs obtained with stimulation at $0.2 \mathrm{~Hz}$. Experiments in $A-C$ were performed in low$\mathrm{Ca}^{2+} /$ high- $\mathrm{Mg}^{2+}$ saline on three different preparations. 


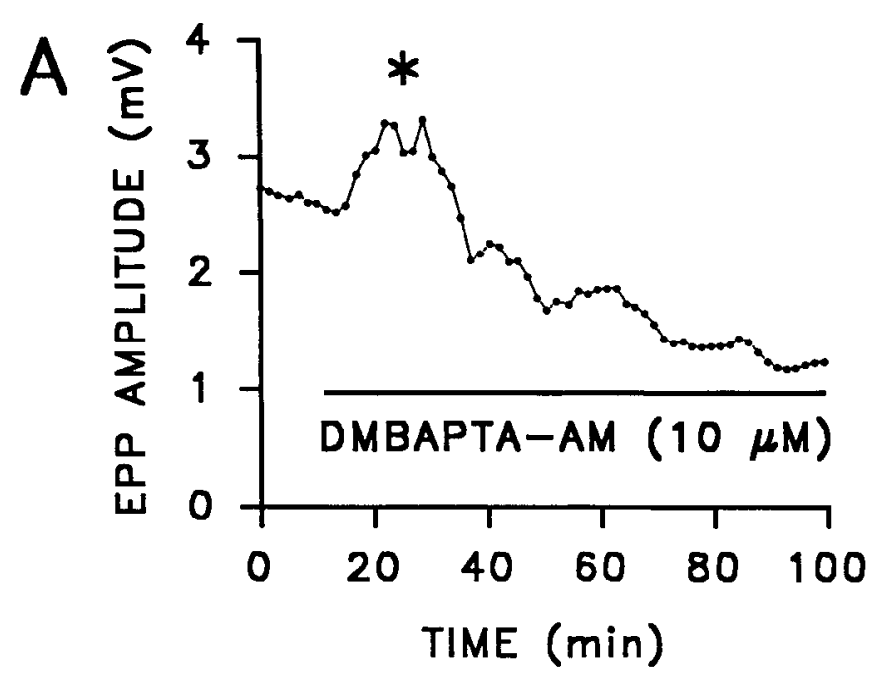

B
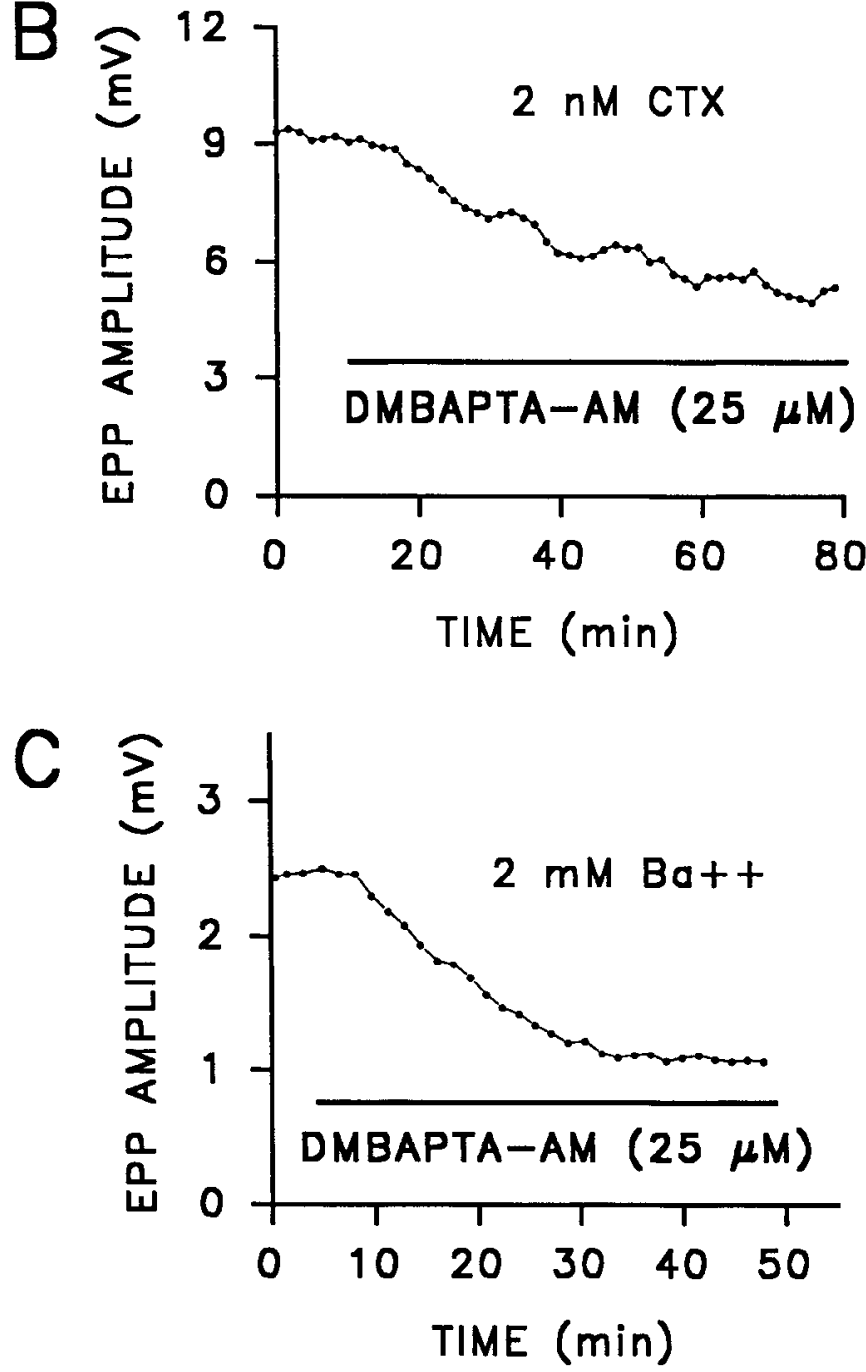

Figure 3. Blockers of gKca channels prevent the early increase of release by $\mathrm{Ca}^{2+}$ chelator. $A$, Application of membrane-permeant $\mathrm{Ca}^{2+}$ buffer $(10 \mu \mathrm{M})($ bar $)$ first increased (asterisk) then decreased transmitter release. $B$, EPP amplitude before and after the application of a membrane-permeant $\mathrm{Ca}^{2+}$ buffer (DMBAPTA-AM, $25 \mu \mathrm{M}$ ) in the presence of CTX ( $2 \mathrm{nM})$. CTX was added to low- $\mathrm{Ca}^{2+} / \mathrm{high}-\mathrm{Mg}^{2+}$ physiological solution $40 \mathrm{~min}$ prior to the buffer. Note the absence of the transient increase of release after the application of the buffer seen in $A$ and Figure 2, $A$ and $B$. Similar results were obtained in five experiments. $C$, EPP amplitude before and after the application of the $\mathrm{Ca}^{2+}$ buffer in the and Martin, 1967; Magleby, 1973). In three experiments, FLUO3-AM did not cause an increase or a decrease in release. In one experiment, CTX was applied after loading with FLUO-3-AM and caused an increase in release. In each experiment the loading of the NMJs was confirmed using the confocal microscope. Thus, while performing its function as an indicator, FLUO-3 did not alter $\mathrm{Ca}^{2+}$ dynamics to the extent that evoked release or gKca was affected. While difficulties in calibrating large, rapidly changing $\mathrm{Ca}^{2+}$ signals with FLUO-3 preclude a rigorous quantitative assessment at this time, we conclude that the increase in transmitter release after blockade of gKca channels by CTX is caused by a larger entry of $\mathrm{Ca}^{2+}$.

\section{CTX does not alter synaptic depression}

The roles of gKca channels in the regulation of synaptic depression were also investigated since this phenomenon may be associated with intracellular accumulation of $\mathrm{Ca}^{2+}$ during repetitive synaptic activity (del Castillo and Katz, 1954; Betz, 1970; Kusano and Landau, 1975; Zucker, 1989). Buildup of $\mathrm{Ca}^{2+}$ due to repetitive nerve activity (Fig. 4; see also Miledi and Parker, 1981; Charlton et al., 1982; Ross et al., 1986) could activate the gKca channels, which then would reduce the duration of the AP and therefore limit the entry of $\mathrm{Ca}^{2+}$. This progressive spike narrowing would result in a reduction in transmitter release and cause depression. We hypothesize that if synaptic depression is due in part to activation of gKca channels, the blockade of these channels would reduce depression or delay its appearance. Thus, pharmacological blockade of gKca channels would result in a more sustained release during repetitive stimulation. In five experiments in normal extracellular $\mathrm{Ca}^{2+}$, a train of stimuli at $40 \mathrm{~Hz}$ for $20 \mathrm{sec}$ induced a $51.3 \pm 5.46 \%$ depression in EPP amplitude relative to the EPP amplitude before high-frequency stimulation. The amount and time course of depression are reproducible at the same $\mathrm{nmj}$. The recovery of release was complete within $10 \mathrm{~min}$ after the end of the train. CTX was then applied and allowed to equilibrate, and depression was tested again (i.e., about $40-45$ min after the control train of stimuli). After blockade of gKca channels with CTX (2 or $10 \mathrm{~nm}$ ), the amount of depression after the train of stimuli was $55.4 \pm 2.56 \%$ ( $n=5$; same five $n$ mjs as used for control) and was not significantly different from controls $(p>0.05$, Student's $t$ test). In addition, in any given synapse, the development of depression during stimulation followed a similar time course before and after application of CTX (Fig. 5A). Similar results were obtained using stimulus trains of higher frequency $(100 \mathrm{~Hz}$ for $10 \mathrm{sec})$, which produce greater $\mathrm{Ca}^{2+}$ entry than the lower-frequency trains (Robitaille and Charlton, unpublished observations using FLUO-3 as described above). The amount of depression, with this paradigm, was the same before and after application of CTX $(n=3 ; 82.5 \%$ before and $84.2 \%$ after; $p>$ 0.05 , Student's $t$ test; different preparations than used for $40 \mathrm{~Hz}$ trains), and there was also little difference in the time course of the development of synaptic depression (Fig. 5B). Because de-

\section{$\leftarrow$}

presence of $\mathrm{Ba}^{2+}(2 \mathrm{~mm})$. Similar results were obtained in four experiments. Note again the absence of the buffer-induced transient increase in transmitter release. $A-C$ are from different nmjs. All these experiments were performed in low-Ca ${ }^{2+} /$ high- $\mathrm{Mg}^{2+}$ saline. Each point in $A-$ $C$ represents the average of 16 EPPs obtained with stimulation at 0.2 $\mathrm{Hz}$. 

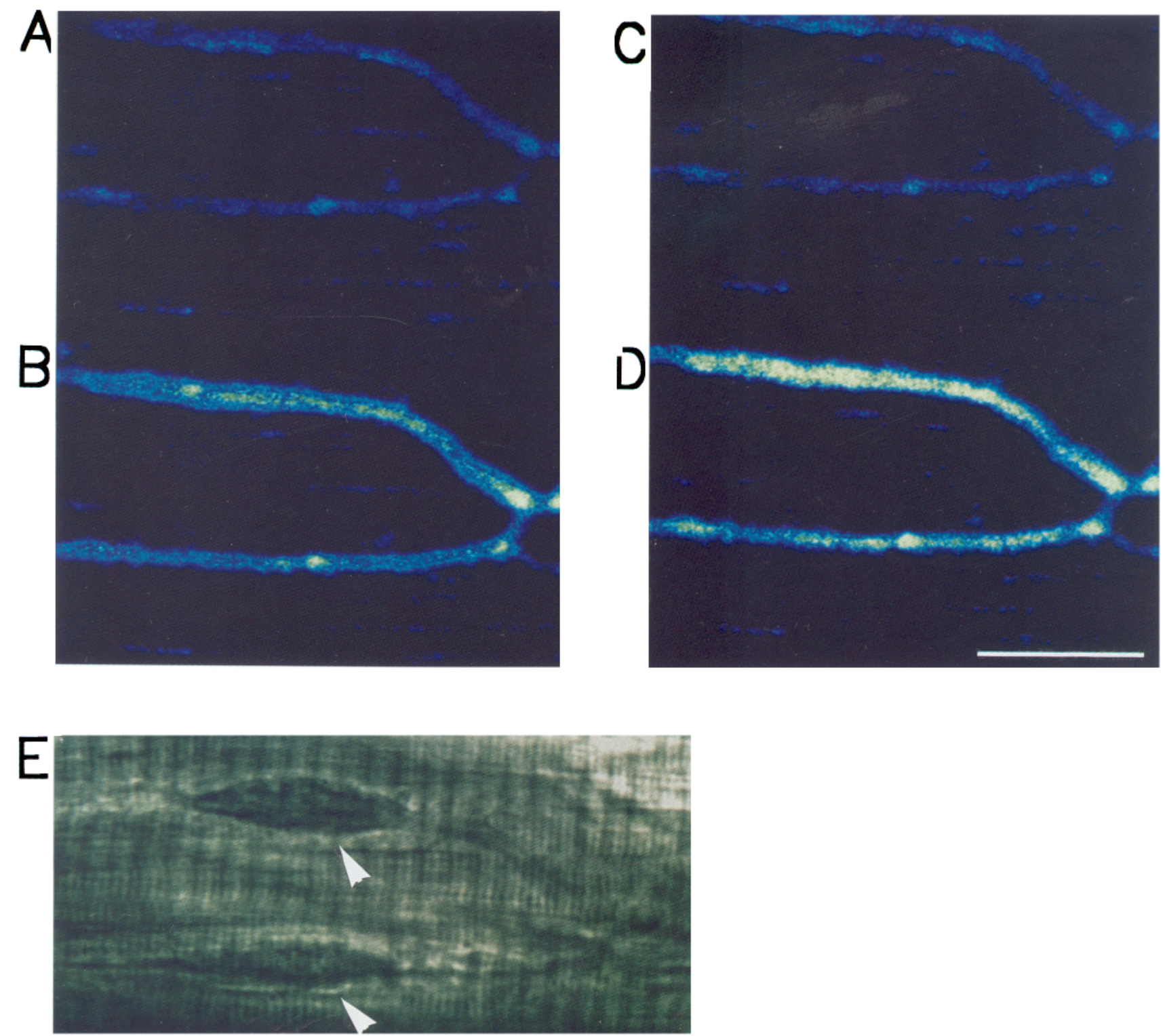

Figure 4. CTX increases $\mathrm{Ca}^{2+}$ entry in nerve terminals. $A-D$, False color images of a frog nmj loaded with the Ca ${ }^{2+}$ indicator FLUO-3-AM. $A$ and $B, \mathrm{Ca}^{2+}$ signal before and $1 \mathrm{sec}$ after the beginning of a train of stimuli $(200 \mathrm{~Hz}) . C$ and $D, \mathrm{Ca}^{2+}$ signal before and 1 sec after the beginning of stimulation at $200 \mathrm{~Hz}, 15 \mathrm{~min}$ after application of CTX $(10 \mathrm{nM})$ to block gKca channels. The stimulus-induced increase of fluorescence due to $\mathrm{Ca}^{2+}$ entry was more pronounced when gKca channels were blocked. Similar results were obtained in two other experiments. $E$, Transmitted light image of the same portion of the same frog $\mathrm{nmj}$ as in $A-D$. Note the presence of two Schwann cell nuclei (arrows). Vertical lines are the sarcomeres of the underlying muscle fiber. $E$ is a nonconfocal image made with the transmitted light attachment of the BioRad 600 microscope. Scale bar, $20 \mu \mathrm{m}$.

pression was not affected by CTX, we conclude that gKca channels are not major regulators of synaptic depression.

Before depression was evident with $40 \mathrm{~Hz}$ stimulation, there was a facilitation of EPPs of about $40 \%$ (Fig. $5 \mathrm{~A}$ ). Since the amount of this facilitation was not affected by CTX, it seems that facilitation is not regulated by the gKca channels.

\section{Discussion}

This article describes the physılogical roles of CTX-sensitive but apamin-insensitive gKca channels at the presynaptic terminal of frog neuromuscular synapses, where these channels help regulate the release of neurotransmitter. We propose that gKca channels normally induce spike narrowing and that their blockade results in broadening of the presynaptic AP, inducing a larger $\mathrm{Ca}^{2+}$ entry in the nerve terminal and thus increasing transmitter release.

\section{Can gKca channels in presynaptic terminal regulate APs?}

The presence of gKca currents in presynaptic terminals of frog (David and Yaari, 1986; A. J. Anderson et al., 1988), lizard (Lindgren and Moore, 1989), and mouse (Mallart, 1985; A. J. Anderson et al., 1988) nmjs was established using extracellular recording of terminal currents. In all of these experiments, voltage-dependent $\mathrm{Na}^{+}$and $\mathrm{K}^{+}$channels were blocked and gKca currents were identified using gKca channel blockers. For instance, CTX blocked $\mathrm{Ca}^{2+}$-dependent outward currents at frog 
nerve terminals (A. J. Anderson et al., 1988), and experiments reported by the supplier of our purified CTX (Alomone Labs) showed that the batch used in our experiments also blocked gKca currents at frog nmjs. Blockade of outward currents should result in AP broadening. Indeed, using intracellular recording at the lizard nerve tcrminal axon, Morita and Barrett (1990) showed that CTX induced broadening of the presynaptic AP. Whether APs are regulated by gKca channels depends on the relative amplitude and kinetics of the current these channels produce in comparison to the current produced by the voltagedependent $\mathrm{K}^{+}$channels. For instance, blockade of gKca by extracellular tetraethylammonium at the squid giant synapse does not alter the duration of the presynaptic AP (Augustine and Eckert, 1982).

Morita and Barrett (1990) also showed that injection of BAPTA into the presynaptic terminal of lizard nmjs caused spike broadening. BAPTA also causes spike broadening in CA1 pyramidal neurons of the rat hippocampus (Lancaster and Nicoll, 1987; Storm, 1987b). In rat hippocampus dentate granule neurons, both BAPTA-AM or the direct injection of the salt form of BAPTA were shown to block postspike slow afterhyperpolarization and spike frequency adaptation, both of which are known to be caused by gKca currents (Niesen et al., 1991). Thus, the application of the permeant buffers can serve as an effective substitute for direct injection of the salt form in blocking gKca and therefore could be expected to have caused spike broadening in the $\mathrm{nmj}$.

Although gKca channels are present at many synapses, the presynaptic AP may not always be sensitive to $\mathrm{Ca}^{2+}$ buffers. For instance, intracellular injection of the salt form of the buffer or application of the membrane-permeant form of $\mathrm{Ca}^{2+}$ buffers did not alter the amplitude and duration of the presynaptic AP of squid presynaptic terminal (Adler et al., 1991) or crayfish preterminal axon branch (Charlton and Iwanchyshyn, 1986), even though there is evidence for the presence of gKca channels at these synapses (Augustine and Eckert, 1982; Sivaramakrishnan et al., in press).

\section{gKca channels can regulate transmitter release}

In the studies on vertebrate nmjs discussed above, synaptic transmission could not be measured because the ACh receptors were blocked with curare so that the postsynaptic currents would not interfere with the detection of the presynaptic events.

In our experiments, CTX applied in normal $\mathrm{Ca}^{2+}$ saline, with no other drugs, increased transmitter release twofold. In an earlier attempt to study the role of gKca channels in synaptic transmission, A. J. Anderson et al. (1988) showed that CTX had no effect on transmitter release at frog and mouse nmjs unless voltage-gated $\mathrm{K}^{+}$channels were blocked by $3,4 \mathrm{DAP}$, and then only a small, temporary, increase of release was induced by CTX. The differences between their results and the present data are not understood, but in any case, they did not find an effect of their toxin fractions on release in the absence of other drugs as we did.

We observed that the application of the permeant chelator DMBAPTA-AM caused a temporary increase in transmitter release. A similar early increase of synaptic responses was observed in some rat hippocampal dentate granule neurons when the membrane-permeant form of BAPTA was applied and the perforant pathway stimulated (Niesen et al., 1991). These early increases may indicate that the buffer caused temporary AP broadening in the presynaptic terminal. gKca channels have also
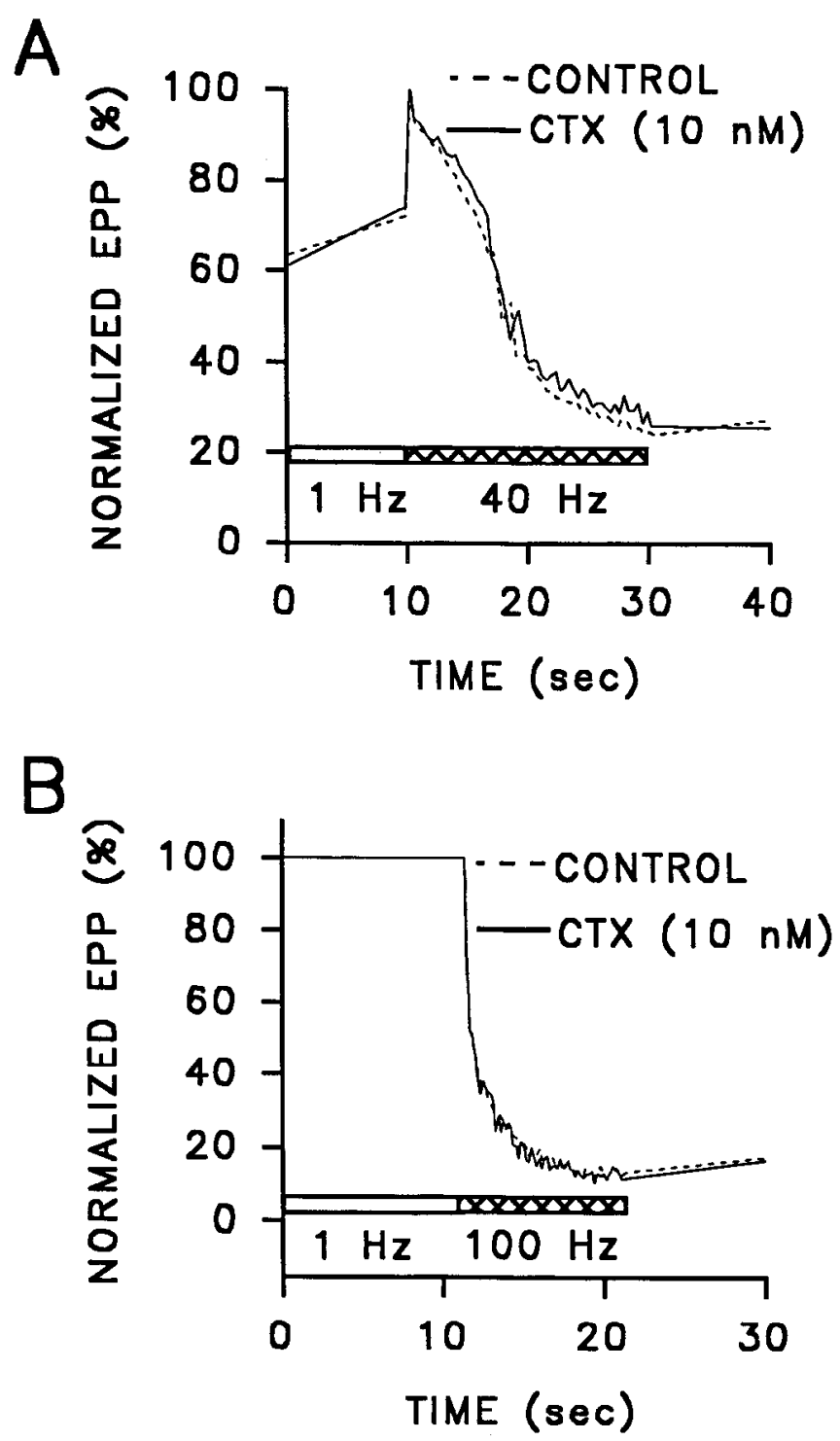

Figure 5. CTX does not affect synaptic depression. For comparison of the time course of depression, EPP amplitude is presented as the percentage of the largest EPP. $A$, EPPs were measured at $1 \mathrm{~Hz}$ for 10 sec before application of $40 \mathrm{~Hz}$ stimulation for $20 \mathrm{sec}$ (broken line). CTX (10 nM) was then applied for $40 \mathrm{~min}$, and the stimulation was repeated in presence of CTX (solid line). Similar results were obtained in five experiments. Transmitter release was approximately doubled by CTX. $B$, EPPs were measured at $1 \mathrm{~Hz}$ for $10 \mathrm{sec}$ before application of a $100 \mathrm{~Hz}$ stimuli for $10 \mathrm{sec}$ (broken line). CTX (10 nM) was then applied for $40 \mathrm{~min}$, and the stimulation was repeated in the presence of CTX (solid line). This is a different nmj than $A$. Similar results were obtained in three experiments. Transmitter release was approximately doubled by CTX. No signal averaging was used in $A$ and $B$.

been described in the squid giant synapse, where they do not regulate release (Augustine and Eckert, 1982), in the active zones of hair cells (Roberts ct al., 1990), and in mammalian brain synaptosomes (Bartschat and Blaustein, 1985).

\section{gKca channels regulate $\mathrm{Ca}^{2+}$ entry}

The electrophysiological experiments indicate that blockade of gKca channels increases transmitter release, and we infer from the work of others that this is due to broadening of the presynaptic AP. The optophysiological experiments, using an intraterminal $\mathrm{Ca}^{2+}$ indicator, show that stimulus-dependent $\mathrm{Ca}^{2+}$ 
entry into the presynaptic terminal increases following blockade of gKca channels with CTX, as would be expected if the duration of the presynaptic AP had increased. This extra $\mathrm{Ca}^{2+}$ entry should increase transmitter release. Therefore, we conclude that, under normal conditions, gKca channels in the presynaptic membrane cause spike narrowing and thus limit $\mathrm{Ca}^{2+}$ entry and transmitter release. Another case of AP regulation by $\mathrm{K}^{+}$channels occurs in pituitary nerve terminals. Here, repetitive stimulation causes AP broadening and increasing secretion (Bourque, 1991) associated with reduction of other $\mathrm{K}^{+}$currents and increased $\mathrm{Ca}^{2+}$ signals (Jackson et al., 1991). Because CTX did not increase MEPP frequency or the resting $\mathrm{Ca}^{2+}$ signal at the $n m j$, it is unlikely that the toxin affects $\mathrm{Ca}^{2+}$ channels or pumps.

\section{gKca channels are close to $\mathrm{Ca}^{2+}$ channels}

In order to affect the AP, the gKca channels must be activated within the $1 \mathrm{msec}$ duration of the AP (Morita and Barrett, 1990). Because $\mathrm{Ca}^{2+}$ diffuses slowly in cytoplasm (Hodgkin and Keynes, 1957; Gorman and Thomas, 1980; Nasi and Tillotson, 1985; Chang, 1986), the gKca channels must be located close to the $\mathrm{Ca}^{2+}$ channels in order to be activated within $1 \mathrm{msec}$ (Lancaster and Nicoll, 1987; Roberts et al., 1990). The clusters of $\mathrm{Ca}^{2+}$ channels at active zones (Roberts et al., 1990; Robitaille et al., 1990; Cohen et al., 1991) can provide the large $\mathrm{Ca}^{2+}$ concentration needed to activate gKca channels (Magleby and Pallotta, 1983), and since they are probably located close to one another, it is possible that both gKca channels and $\mathrm{Ca}^{2+}$ channels are located in the double rows of particles at the active zones seen in freeze-fracture preparations of the frog nmj (Dreyer et al., 1973). However, proof of the exact location of gKca channels at active zones of frog nmjs must await direct visualization with labeled ligands.

Intracellular $\mathrm{Ca}^{2+}$ buffer increased transmitter release apparently by preventing the activation of gKca channels. It appears, then, that gKca channels are more affected by lower buffer concentration than is transmitter release. We speculate that this may indicate that these channels are more distant from $\mathrm{Ca}^{2+}$ channels than are the $\mathrm{Ca}^{2+}$ receptors that trigger release. Alternatively, the gKca channels may require higher $\mathrm{Ca}^{2+}$ levels for activation and may have different binding rates than do the release trigger receptors (Niesen et al., 1991). In any case, $\mathrm{Ca}^{2+}$ buffers may be useful tools for separating $\mathrm{Ca}^{2+}$-stimulated cell activities.

\section{Depression is not regulated by gKca channels}

While we cannot rule out possible interactions between CTX effects on AP broadening and EPP amplitude dependence of depression (Zucker, 1989), we note that CTX did not affect the time course of depression. The failure of CTX to affect synaptic depression indicates that gKca channels are not major regulators of this phenomenon. One possible interpretation of these results is that gKca channels are already fully activated by the intense $\mathrm{Ca}^{2+}$ transient caused by a single presynaptic AP and therefore a further increase in $\mathrm{Ca}^{2+}$ concentration due to residual $\mathrm{Ca}^{2+}$ does not modify their activity.

\section{Summary}

gKca channels in these presynaptic terminals can regulate phasic synaptic transmission by controlling the duration of the presynaptic $\mathrm{AP}$, and hence these channels help regulate $\mathrm{Ca}^{2+}$ entry in the ncrve terminal. We speculate that this mechanism could function as a negative feedback system that stabilizes $\mathrm{Ca}^{2+}$ entry if the concentration in the synaptic cleft is altered (see Attwell and Iles, 1979, for a discussion of ion concentration changes in the synaptic cleft). Therefore, our data reveal yet another role of gKca channels in addition to the ones already known in the CNS, such as the regulation of nerve cell excitability (Marty, 1989). As pointed out by Morita and Barrett (1990), the activation of gKca channels during normal activity may help prevent the occurrence of repetitive nerve terminal discharge.

At synapses where $I_{\mathrm{Kc}}$ is large enough to regulate the AP, transmitter release will be influenced by the various factors that modulate these currents such as the number of gKca channels, their distribution relative to the $\mathrm{Ca}^{2+}$ channels and the release apparatus, and finally, their phosphorylation state (de Payer et al., 1982; Kaczmarek, 1988).

\section{References}

Adler EM, Augustine GJ, Duffy SN, Chariton MP (1991) Alien intracellular calcium chelators attenuate neurotransmitter release at the squid giant synapse. J Neurosci 11:1496-1507.

Anderson AJ, Harvey AL, Rowan EG, Strong PN (1988) Effects of charybdotoxin, a blocker of $\mathrm{Ca}^{2+}$-activated $\mathrm{K}^{+}$channels, on motor nerve terminals. Br J Pharmacol 95:1329-1335.

Anderson CS, MacKinnon R, Smith C, Miller C (1988) Charybdotoxin block of single $\mathrm{Ca}^{2+}$-activated $\mathrm{K}^{+}$channels. J Gen Physiol 91:317333.

Arslan P, Di Virgilio F, Beltrame M, Tsien RY, Pozzan T (1985) Cytosolic $\mathrm{Ca}^{2+}$ homeostasis in Ehrlich and Yoshida carcinomas. J Biol Chem 260:2719-2727.

Attwell D, Iles JF (1979) Synaptic transmission: ion concentration changes in the synaptic cleft. Proc R Soc Lond [Biol] 206:1 15-131.

Augustine GJ (1990) Regulation of transmitter release at the squid giant synapse by presynaptic delayed rectifier potassium current. $\mathbf{J}$ Physiol (Lond) 431:343-364.

Augustine GJ, Charlton MP (1986) Calcium dependence of presynaptic calcium current and post-synaptic response at the squid giant synapse. J Physiol (Lond) 381:619-640.

Augustinc GJ, Eckert R (1982) Calcium-dependent potassium current in squid presynaptic nerve terminals. Biol Bull 163:397.

Augustine GJ, Charlton MP, Smith SJ (1985) Calcium entry and transmitter release at voltage-clamped nerve terminals of squid. J Physiol (Lond) 367:163-181.

Augustine GJ, Charlton MP, Smith SJ (1987) Calcium action in synaptic transmitter release. Annu Rev Neurosci 10:633-693.

Bartschat DK, Blaustein MP (1985) Calcium-activated potassium channels in isolated presynaptic nerve terminals from rat brain. J Physiol (Lond) 361:441-457.

Betz WJ (1970) Depression of transmitter release at the neuromuscular junction of the frog. J Physiol (Lond) 206:629-644.

Blatz AL, Magleby KL (1987) Calcium-activated potassium channels. Trends Neurosci 10:463-467.

Bourque CW (1991) Activity-dependent modulation of nerve terminal excitation in a mammalian peptidergic system. Trends Neurosci 14 28-30.

Castle NA, Strong PN (1986) Identification of two toxins from scorpion (Leirus quinquestriatus) venom which block distinct classes of calcium-activated potassium channel. FEBS Lett 209:117-121.

Castle NA, Haylett DG, Jenkinson DH (1989) Toxins in the characterization of potassium channels. Trends Neurosci 12:59-65.

Chang DC (1986) Axonal transport and the movement of ${ }^{45} \mathrm{Ca}$ inside the giant axon of squid. Brain Res 367:319-322.

Charlton MP, Iwanchyshyn GJ (1986) Exogenous calcium buffer reduces synaptic transmitter release and facilitation. Soc Neurosci Abstr 12:817.

Charlton MP, Smith SJ, Zucker RS (1982) Role of presynaptic calcium ions and channels in synaptic facilitation and depression at the squid giant synapse. J Physiol (Lond) 323:173-193.

Cohen MW, Jones OT, Angelides KJ (1991) Distribution of $\mathrm{Ca}^{2+}$ channels on frog motor nerve terminals revealed by fluorescent $\omega$-conotoxin. J Neurosci 11:1032-1039.

Cruz LJ, Gray WR, Olivera BM, Zeikus RD, Kerr L, Yoshikami D, Moczydlowski E (1985) Conus geographus toxins that discriminate between neuronal and muscle sodium channels. J Biol Chem 260: 9280-9288. 
David G, Yaari Y (1986) Several potassium conductances modulate the excitability of frog motor nerve terminals. In: Calcium, neuronal function and transmitter release (Rahamimoff $\mathrm{R}$, Katz B, eds), pp 563-574. Boston: Martinus Nijhoff.

del Castillo J, Katz B (1954) Statistical factors involved in neuromuscular facilitation and depression. J Physiol (Lond) 124:574-585.

de Peyer JE, Cachelin AB, Levitan IB, Reuter H (1982) $\mathrm{Ca}^{2+}$-activated $\mathrm{K}^{+}$conductance in internally perfused snail neurons is enhanced by protein phosphorylation. Proc Natl Acad Sci USA 79:4207-4211.

Dodge FA, Rahamimoff R (1967) Co-operative action of calcium ions in transmitter release at the neuromuscular junction. J Physiol (Lond) 193:419-432.

Dreyer F, Peper K, Akert K, Sandri C, Moor H (1973) Ultrastructure of the 'active zone' in the frog neuromuscular junction. Brain Res 62: 373-380.

Ewald DA, Levitan IB (1987) Ion channels regulated by calcium. In: Neuromodulation: the biochemical control of neuronal excitability (Kaczmarek LK, Levitan IB, eds), pp 138-158. New York: Oxford UP.

Garciá-Sancho J (1985) Pyruvate prevents the ATP depletion caused by formaldehyde or calcium-chelator esters in the human red cell. Biochim Biophys Acta 813:148-150.

Gimenez-Gallego G, Navia MA, Reuben JP, Katz GM, Kaczorowski GJ, Garcia ML (1988) Purification, sequence, and model structure of charybdotoxin, a potent selective inhibitor of calcium-activated potassium channels. Proc Natl Acad Sci USA 85:3329-3333.

Goh JW, Pennefather PS (1987) Pharmacological and physiological properties of the after-hyperpolarization current of bullfrog ganglion neurones. J Physiol (Lond) 394:315-330.

Gorman ALF, Thomas MV (1980) Intracellular calcium accumulation during depolarization in a molluscan neurone. J Physiol (Lond) 308: 259-285.

Gray WR, Olivera BM (1988) Peptide toxins from venomous Conus snails. Annu Rev Biochem 57:665-700.

Hodgkin AL, Keynes RD (1957) Movements of labelled calcium in squid giant axons. J Physiol (Lond) 138:253-281.

Jackson MB, Konnerth A, Augustine GJ (1991) Action potential broadening and frequency-dependent facilitation of calcium signals in pituitary nerve terminals. Proc Natl Acad Sci USA 88:380-384.

Kaczmarek LK (1988) The regulation of neuronal calcium and potassium channels by protein phosphorylation. In: Advances in second messenger and phosphoprotein research (Greengard P, Robison GA, eds), pp 113-138. New York: Raven.

Katz B, Miledi R (1968) The role of calcium in neuromuscular facilitation. J Physiol (Lond) 195:481-492.

Kerr LM, Yoshikami D (1984) A venom peptide with a novel presynaptic blocking action. Nature 308:282-284.

Kirsch GE, Narahashi T (1978) 3,4-Diaminopyridine. A potent new potassium channel blocker. Biophys J 22:507-512.

Kusano K, Landau EM (1975) Depression and recovery of transmission at the squid giant synapse. $J$ Physiol (Lond) 245:13-32.

Lancaster B, Nicoll RA (1987) Properties of two calcium-activated hyperpolarizations in rat hippocampal neurones. $J$ Physiol (Lond) 389:187-203.

Latorre R, Oberhauser A, Labarca P, Alvarez O (1989) Varieties of calcium-activated potassium channels. Annu Rev Physiol 51:385399.

Lindgren CA, Moore JW (1989) Identification of ionic currents at presynaptic nerve endings of the lizard. J Physiol (Lond) 414:201222.

Llinás R, Steinberg IZ, Walton K (1981) Presynaptic calcium currents in squid giant synapse. Biophys J 33:289-322.

Llinás R, Sugimori M, Simon SM (1982) Transmission by presynaptic spike-like depolarization in the squid giant synapse. Proc Natl Acad Sci USA 79:2415-2419.

MacKinnon R, Miller C (1988) Mechanism of charybdotoxin block of the high-conductance, $\mathrm{Ca}^{2+}$-activated $\mathrm{K}^{+}$channel. J Gen Physiol 91:335-349.

Magleby KL (1973) The effect of repetitive stimulation on facilitation of transmitter release at the frog neuromuscular junction. J Physiol (Lond) 234:327-352.

Magleby KL, Pallotta BS (1983) Calcium dependence of open and shut interval distributions from calcium-activated potassium channels in cultured rat muscle. J Physiol (Lond) 344:585-604.

Mallart A (1985) A calcium-activated potassium current in motor nerve terminals of the mouse. J Physiol (Lond) 368:577-591.

Mallart A, Martin AR (1967) An analysis of facilitation of transmitter release at the neuromuscular junction of the frog. J Physiol (Lond) 193:679-694.

Marty A (1989) The physiological role of calcium-dependent channels. Trends Neurosci 12:420-424.

Massefski W, Redfield AG, Hare DR, Miller C (1990) Molecular structure of charybdotoxin, a pore-directed inhibitor of potassium ion channels. Science 249:521-524.

Miledi R, Parker I (1981) Calcium transients recorded with arsenazo III in the presynaptic terminal of the squid giant synapse. Proc R Soc Lond [Biol] 212:197-211

Morita K, Barrett EF (1990) Evidence for two calcium-dependent potassium conductances in lizard motor nerve terminals. J Neurosci 10:2614-2625.

Nasi E, Tillotson D (1985) The rate of diffusion of $\mathrm{Ca}^{2+}$ and $\mathrm{Ba}^{2+}$ in a nerve cell body. Biophys J 47:735-738.

Niesen C, Charlton MP, Carlen PL (1991) Postsynaptic and presynaptic effects of the calcium chelator BAPTA on synaptic transmission in rat hippocampal dentate granule neurons. Brain Res 555:319-325.

Rhoda MD, Giraud F, Craescu CT, Beuzard Y (1985) Compartmentalization of $\mathrm{Ca}^{2+}$ in sickle cells. Cell Calcium 6:397-411.

Rink TJ, Tsien RY, Pozzan T (1982) Cytoplasmic pH and free $\mathbf{M g}^{2+}$ in lymphocytes. J Cell Biol 95:189-196.

Roberts WM, Jacobs RA, Hudspeth AJ (1990) Colocalization of ion channels involved in frequency selectivity and synaptic transmission at presynaptic active zones of hair cells. J Neurosci 10:3664-3684.

Robitaille R, Adler EM, Charlton MP (1990) Strategic location of calcium channels at transmitter release sites of frog neuromuscular synapses. Neuron 5:773-779.

Ross WN, Stockbridge LL, Stockbridge NL (1986) Regional properties of calcium entry in barnacle neurons determined with arsenazo III and a photodiode array. J Neurosci 6:1148-1159.

Schweitz H, Bidard J-N, Maes P, Lazdunski M (1989) Charybdotoxin is a new member of the $\mathrm{K}^{+}$channel toxin family that includes dendrotoxin I and mast cell degranulating peptide. Biochemistry 28:97089714.

Shotton DM (1989) Confocal scanning optical microscopy and its applications for biological specimens. J Cell Sci 94:175-206.

Silinsky EM (1978) On the role of barium in supporting the asynchronous release of acetylcholine quanta by motor nerve impulses. J Physiol (Lond) 274:157-171.

Simon SM, Llinás RR (1985) Compartmentalization of the submembrane calcium activity during calcium influx and its significance in transmitter release. Biophys J 48:485-498.

Sivaramakrishnan S, Bittner GD, Brodwick MS (in press) Calciumactivated potassium conductance in presynaptic terminals at the crayfish neuromuscular junction. J Gen Physiol, in press.

Smith C, Phillips M, Miller C (1986) Purification of charybdotoxin, a specific inhibitor of the high-conductance $\mathrm{Ca}^{2+}$-activated $\mathrm{K}^{+}$channel. J Biol Chem 261:14607-14613.

Smith SJ, Augustine GJ (1988) Calcium ions, active zones and synaptic transmitter release. Trends Neurosci 11:458-464.

Storm JF (1987a) Action potential repolarization and a fast aftcrhyperpolarization in rat hippocampal pyramidal cells. J Physiol (Lond) 385:733-759.

Storm JF (1987b) Intracellular injection of a $\mathrm{Ca}^{2+}$ chelator inhibits spike repolarization in hippocampal neurons. Brain Res 435:387392.

Sugg EE, Garcia ML, Reuben JP, Patchett AA, Kaczorowski GJ (1990) Synthesis and structural characterization of charybdotoxin, a potent peptidyl inhibitor of the high conductance $\mathrm{Ca}^{2+}$-activated $\mathrm{K}^{+}$channel. J Biol Chem 265:18745-18748.

Tsien RY (1981) A non-disruptive technique for loading calcium buffers and indicators into cells. Nature 290:527-528.

Tsien RY (1989) Fluorescent probes of cell signaling. Annu Rev Neurosci 12:227-253.

Zucker RS (1989) Short-term synaptic plasticity. Annu Rev Neurosci $12: 13-31$ 